\title{
Strength Behavior of Flat and Folded Fly Ash-Based Geopolymer Ferrocement Panels under Flexure and Impact
}

\author{
Dharmar Sakkarai $\mathbb{D}^{1}$ and Nagan Soundarapandian $\mathbb{D}^{2}$ \\ ${ }^{1}$ Department of Civil Engineering, Ramco Institute of Technology, Rajapalayam 626117, Tamilnadu, India \\ ${ }^{2}$ Department of Civil Engineering, Thiagarajar College of Engineering, Madurai 625015, Tamilnadu, India
}

Correspondence should be addressed to Dharmar Sakkarai; dharmar.msd7@gmail.com

Received 26 July 2021; Revised 11 September 2021; Accepted 26 October 2021; Published 12 November 2021

Academic Editor: Peng Zhang

Copyright (c) 2021 Dharmar Sakkarai and Nagan Soundarapandian. This is an open access article distributed under the Creative Commons Attribution License, which permits unrestricted use, distribution, and reproduction in any medium, provided the original work is properly cited.

\begin{abstract}
This paper presents the impact of fiber and wire mesh layers on the strength behavior of flat as well as folded fly ash-based geopolymer ferrocement panels. The behaviors, namely, flexural strength, impact strength, ductility, stiffness, and cracking patterns, are observed. With the objective of decreasing $\mathrm{CO}_{2}$ emissions, concrete utilizes wastes such as fly ash disposed by industrial sectors. Six panels (three flat and three folded) were cast utilizing a fly ash-dependent geopolymer mortar of size $1000 \mathrm{~mm} \times 400 \mathrm{~mm} \times 30 \mathrm{~mm}$ in addition to two panels of each type for the impact study. Heat curing in a temperature-controlled chamber maintaining $75^{\circ} \mathrm{C}$ to $80^{\circ} \mathrm{C}$ for 24 hours was done after 24 hours of the resting period. The experimental results indicated that the flexural strength got enhanced by 33 percent by increasing the quantity of wire mesh layers, but the ductility got decreased by 30 percent for the flat panels; however, there was no noticeable impact in the case of folded panels. The flexural strength of the folded panel was found to be three times greater than that of the flat panels. In addition, it is noticed that the behavior of the fiberreinforced flat as well as folded panels of single layer mesh is stronger than the double layer wire mesh panels regarding cracking and ultimate load. Furthermore, the impact strength of the folded panels was found to be $90 \%$ greater than that of flat panels, and the energy absorbed at failure was directly proportional to the volume of reinforcement provided in the panels. Moreover, the failure pattern of the impact tested specimens showed punching shear as the predominant factor.
\end{abstract}

\section{Introduction}

Ferrocement is a type of reinforced concrete with wire mesh layers and/or small diameter rings, completely coated or encapsulated in mortar. In 1940, the first ferrocement operation of aircraft hangars, ships, and buildings was carried out by Pier Luigi Nervy, Italy's engineer, architect, and builder. This material is extremely durable, cost-effective, and flexible. Geopolymer ferrocement panels have been developed widely as a common building material in the past decades because its manufacturing operation could minimize carbon dioxide emissions by 80 percent relative to the conventional Portland cement production. Davidovits [1] formulated a concrete mixture geopolymer composite material, which could be manufactured through incorporation of a pozzolanic element and often alumina silicate from a high alkaline solution. Fly ash, which is readily accessible from coal power plants, has become an ideal primary substance for alumina silicate. It also exhibits ceramic-like properties, such as good fire resistance at high temperatures. In addition to this, the advantages compared to OPC concrete include resistance to acid attack, strong bonding intensity, and higher corrosion resistance, as well as reduced creep and shrinkage. Abdulla et al. [2] quantitatively illustrated the functioning and chemical reactivity of fly ashbased geopolymer concrete.

Ferrocement is also an environmentally sustainable innovation that has outstanding special features like higher tensile strength, increased durability, elevated cracking resistance, fire resistance, and the capacity to withstand massive deformation prior to actually collapsing. It also proves to be an energy-efficient building material. According to ACI Committee 549 [3], ferrocement is a form of slender wall of moderate thickness built using the hydraulic concrete 
mixture that is combined with wire mesh layers. Two essential parameters are widely used in the characterization of ferrocement, such as the volume fraction of reinforcement and overall bonded reinforcement area per unit composite length. Hexagonal wire mesh, welded wire mesh, woven wire mesh, and three-dimensional mesh are the major categories of wire mesh used in the construction sector. The mesh can be constructed using an appropriate metal or some other products. Thickness varies from $25 \mathrm{~mm}$ to $50 \mathrm{~mm}$. The updated ACI code allows the use of nonmetallic insulation and fiber. Ferrocement finds its application in construction sector, agriculture, water supply systems, etc.

Research suggests that in the scenario of earthquake resistance buildings, this tends to be an outstanding combination. Temuujin et al. [4] investigated experimentally the formulation and characterization of geopolymer mortar made of fly ash by altering the binding material as well as aggregate proportion. Hardjito et al. [5] focused on the low calcium fly ash-dependent geopolymer mortar and its setting duration.

Mahmood and Majeed [6] performed theoretical as well as experimental investigations on the flexural behavior of cement-based ferrocement panels. The work explained the impact of overall strength as well as ductility using varied wire mesh materials. Rajendran and Soundarapandian [7] addressed the theoretical research on the flexural behavior of flat geopolymer ferrocement slabs. The variables investigated were wire mesh layers and the concentration of alkaline solution. Rahman et al. [8] conducted a review on the behavior of polymer fiber as a substitute to metal wire mesh. Their study revealed that the utilization of fiber as the ferrocement reinforcement is technologically feasible and does not have any negative impact on flexural strength.

The influence of curing temperature upon these flexural characteristics of silica-based carbon-reinforced composites was discussed (Tran et al.) [9]. Curing temperature in the range of $70^{\circ} \mathrm{C}$ and $100^{\circ} \mathrm{C}$ was established as an optimum temperature for obtaining a good flexural strength. Hago et al. [10] experimentally studied the flexural strength of optimal and service loaded ferrocement roof slab panels.

Nagan and Mohana [11] studied experimentally the behavior of geopolymer ferrocement slabs subjected to impact by varying the wire mesh layers and concluded that an increase in the volume fraction of reinforcement increases the impact strength. Murali et al. [12] performed an investigation on the impact resistance and strength of fiberreinforced concrete, and the results indicated that the concrete containing fiber gave the best performance under impact loading. Kaliraj et al. [13] investigated the impact strength of geopolymer ferrocement trough panels and found that trough panels are stronger than flat panels.

Due to its high viscosity, a fresh fly ash-based geopolymer's workability could be a major disadvantage. Xie and Kayali [14] investigated the influence of superplasticizer on the workability of fly ash-based geopolymers in Class F and Class C. It found that superplasticizers based on polycarboxylates were successful for Class C fly ash, while superplasticizers based on naphthalene were effective for Class F fly ash.
The primary purpose of this research is to establish an environmentally friendly composite material for construction that can be employed as multipurpose building element that incorporates industrial by-products by exploiting the advantages of both geopolymer as well as ferrocement technologies. Moreover, an attempt is made to study the strength behavior of ferrocement panels under flexure and impact by adjusting the wire mesh layers and integrating fibers into the geopolymer matrix.

\section{Materials and Methods}

2.1. Specimen Geometry. The geometry of the geopolymer ferrocement (GF) panels used in the experimental investigation is shown in Figure 1. The panels had a constant thickness of $30 \mathrm{~mm}$, and the description of the panels is given in Table 1.

2.2. Materials. The constituents of the geopolymer ferrocement are shown in Figure 2.

2.2.1. Geopolymer Mortar. Geopolymer mortar was obtained by synthesizing the pozzolanic component with a combination of activator solution. The ingredients of the freshly prepared concrete consist of fly ash, fine aggregate, and the liquid alkaline activator. Low calcium fly ash (Class F) confirming to IS 3812 (Part 1) [15] and ASTM C618-5 [16], acquired from Tuticorin thermal power plant, has been used as a pozzolanic component, and the chemical properties of fly ash used are provided in Table 2 . Specific gravity as well as fineness of fly ash used is 2.32 and $390.40 \mathrm{~m}^{2} / \mathrm{kg}$, respectively.

24 hours before application, an activator solution was prepared using sodium hydroxide granules and sodium silicate. The amount of sodium hydroxide solids, including the water used to generate sodium hydroxide solution of the specified molarity was extracted in accordance to the guidance provided in Perry's Chemical Engineers' Handbook [17].

River sand passing through $2.36 \mathrm{~mm}$ IS sieve and retained on $150 \mu$ IS sieve of specific gravity 2.57 with a fineness modulus of 2.89 adhering to Zone II of IS 383 [18] was used as the fine aggregate. A water reduction admixture, such as Fosroc Conplast SP430, a chloride free superplasticizing admixture based on selected sulphonated naphthalene polymers, conforming to ASTM-C-494, Type ' $\mathrm{F}$ ', and Type 'A', is employed to provide the required workability. Table 3 shows the mix proportions and the strength of the geopolymer mortar specimens.

2.2.2. Wire Mesh. Wire meshes made of steel were used as prime mesh reinforcement. The characteristics of the resulting ferrocement component are influenced by the size of the mesh, ductility, fabrication, and treatment of the mesh used in the panel [19]. This form of mesh is easily available, affordable, and easy to handle. This mesh is made up of cold drawn wire that is normally twisted into hexagonal patterns. 


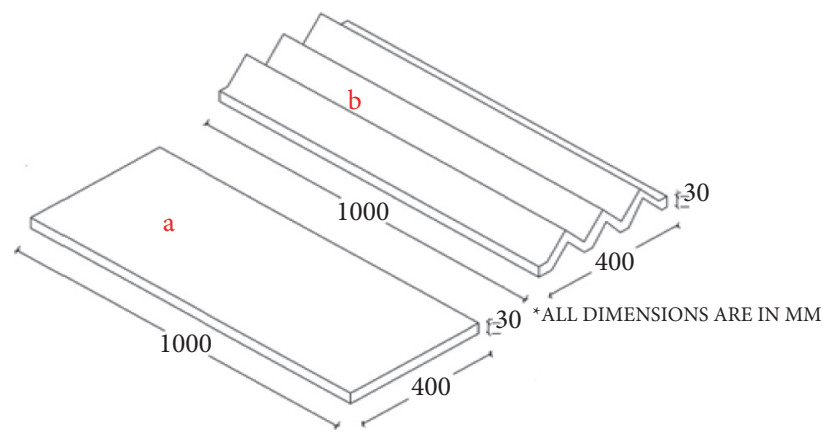

Figure 1: Geometry of GF panels. (a) Flat panel. (b) Folded panel.

Hexagonal mesh including longitudinal wires may contain unique designs. For this work, a galvanized sheet metal wire mesh (termed as chicken wire mesh) with hexagon-shaped grid was used as shown in Figure 2(d). The wire separation distance is $12.50 \mathrm{~mm} \mathrm{c} / \mathrm{c}$ with a width of $0.72 \mathrm{~mm}$ and of about 20 gauges. The steel mesh wire was kept in the optimal position as shown in Figure 3, using a binding string prior to inserting it into the panel mould. The yield strength for chicken wire is $310 \mathrm{~N} / \mathrm{mm}^{2}$. The density fraction of the mesh intensification was determined using the relationship as follows:

$$
V r=\frac{N w_{r}}{h \delta_{r}} .
$$

Here, ' $N$ ' signifies the number of mesh layer, ' $w_{r}$ ' denotes the reinforcement mesh weight, ' $h$ ' represents the element thickness, and ' $\delta_{r}$ ' denotes the reinforcement density.

2.2.3. Steel Fiber. Steel fiber was employed as a secondary reinforcement material. Steel fiber in comparison to prolonged reinforcing bars is short and closely distributed. As a result, additional reinforcing zones could be accomplished by using a reinforcing steel bar grid. Additionally, steel fiber helps in controlling the crack and enhancing the flexural strength, rigidity, and elastic modulus. Crimped steel fiber of length $10 \mathrm{~mm}$ and thickness $0.4 \mathrm{~mm}$ with an aspect ratio of 25 as shown in Figure 2(e) was used.

2.2.4. Skeletal Reinforcement. Skeletal reinforcement (Figure 3) was used on which chicken wire layers would be placed.

2.2.5. Preparation of Geopolymer Mortar. Before mixing, all material quantities were weighed according to the mix design. Alkaline activator solutions (AAS) were made 24 hours ahead of time and allowed to cool to room temperature before mixing and casting. With the aim of combining the weighted materials, a pan mixer was employed. After 3 minutes of dry mixing (fly ash, sand, and fiber), alkaline liquid was added to the combination. In addition, a superplasticizer was added to the solution after being diluted in extra water. The wet mixing took another 4 minutes. It was then poured into the moulds to make geopolymer mortar specimens.
TABLE 1: Description of GF panels.

\begin{tabular}{lc}
\hline Description of the panels & Panel ID \\
\hline GF flat panel with single layer mesh & GFP-FT-01- \\
& OC \\
GF flat panel with double layer mesh & GFP-FT-02- \\
Fiber-reinforced GF flat panel with single layer & OC \\
mesh & OCP-FR-FT- \\
GF-folded panel with single layer mesh & GFP-FD-01- \\
& OC \\
GF-folded panel with double layer mesh & GFP-FD-02- \\
Fiber-reinforced GF-folded panel with single & OC \\
layer mesh & GFP-FR-FD- \\
\hline
\end{tabular}

2.3. Specimen Casting and Curing. Steel moulds (Figure 4), which are properly lubricated were used for flat as well as folded panels. After setting the reinforcement in place, the prepared geopolymer mortar was poured and compacted well. A consistency test was performed using flow table testing according to BS: EN 1015-3 [20]. Mortar cubes of dimensions $70.6 \mathrm{~mm} \times 70.6 \mathrm{~mm} \times 70.6 \mathrm{~mm}$ were also cast to evaluate the characteristic stiffness of the geopolymer mixture. After 24 hours, the panels were demoulded and exposed to heat curing in a custom-designed heat curing chamber (Figure 5) for 24 hours at $75^{\circ} \mathrm{C}$ to $80^{\circ} \mathrm{C}$.

\subsection{Experiment Methods}

2.4.1. Compressive Strength Test. The compressive strength of geopolymer mortar cubes representing corresponding mixes was done in accordance with IS 4031 (Part 6) [21] in a compressive testing machine of $1000 \mathrm{kN}$ capacity (Figure 6(a)).

2.4.2. Ultrasonic Pulse Velocity Test. To check the quality and homogeneity of the panels, an ultrasonic pulse velocity test was carried out (Figure 7). This test was conducted by passing ultrasonic pulses through the panels and by measuring the time taken by the pulse to get through the structure. Higher velocities indicate good quality and continuity of the material, while lower velocities may indicate that the panel have cracks or voids. 


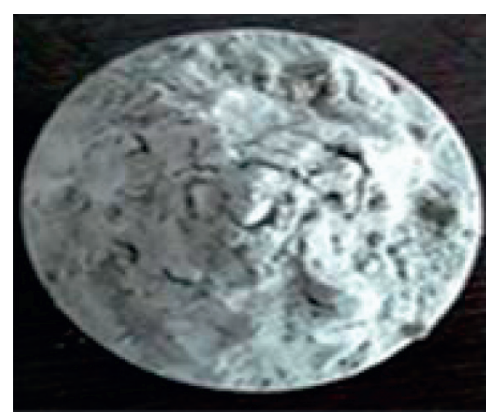

(a)

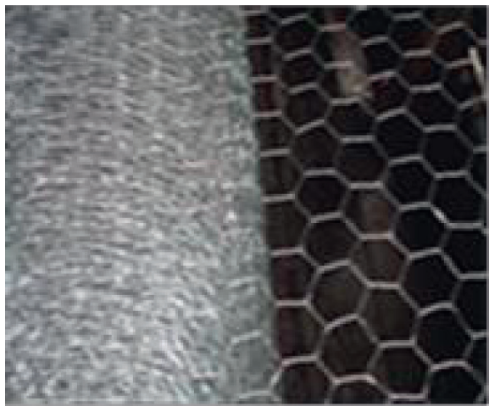

(d)

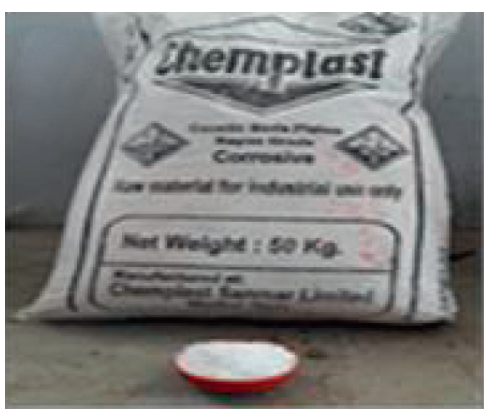

(b)

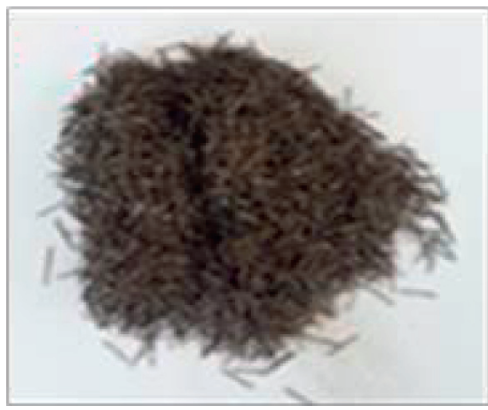

(e)

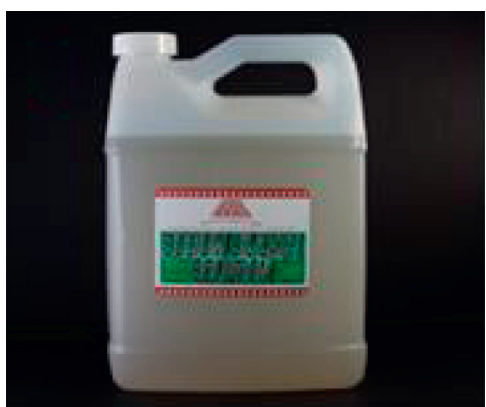

(c)

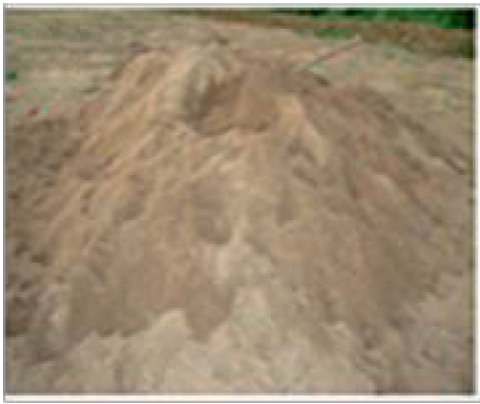

(f)

Figure 2: Constituents of geopolymer ferrocement. (a) Fly ash. (b) Sodium hydroxide. (c) Sodium silicate. (d) Wire mesh. (e) Steel fiber. (f) River sand.

TABle 2: Chemical compositions of low calcium fly ash.

\begin{tabular}{lcc}
\hline Characteristics & Composition by \% weight & Specifications as per IS 3812:2003 \\
\hline Aluminium dioxide $\left(\mathrm{Al}_{2} \mathrm{O}_{3}\right)$ plus iron oxide $\left(\mathrm{as} \mathrm{Fe}_{2} \mathrm{O}_{3}\right)$ & 35.99 & Minimum 70 \\
Silicon oxide $\left(\right.$ as $\left.\mathrm{SiO}_{2}\right)$ & 59.10 & - \\
Magnesium oxide $(\mathrm{as} \mathrm{MgO})$ & 1.29 & Max 3 \\
Total sulphur as sulphur trioxide $\left(\mathrm{SO}_{3}\right)$ & 0.61 & Max 1.5 \\
Alkalis as sodium oxide $\left(\mathrm{Na}_{2} \mathrm{O}\right)$ & 0.20 & Max 5 \\
Calcium oxide as $\mathrm{CaO}$ & 2.25 & Max 5 \\
Loss on ignition & 0.48 & \\
\hline
\end{tabular}

TABLE 3: Mix proportions of the geopolymer mortar.

\begin{tabular}{lcc}
\hline Mortar type & Proportions & Compressive strength $\left(\mathrm{N} / \mathrm{mm}^{2}\right)$, after 24 hours of curing at \\
$75^{\circ} \mathrm{C}$ to $80^{\circ} \mathrm{C}$
\end{tabular}

2.4.3. Flexural Test. The fabricated panels were tested in a hydraulic power packed loading frame employing load cells and 16 channel LVDT under two-point loading conditions. While loading, the crack pattern obtained was also observed and marked. Furthermore, the yield strength and corresponding deflection were recorded.

The flexure testing carried out on the flat panel is shown in Figure 8. 


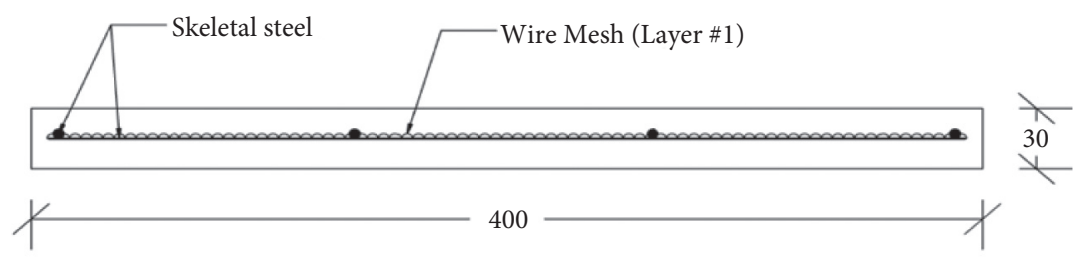

FLAT PANEL WITH SINGLE LAYER MESH

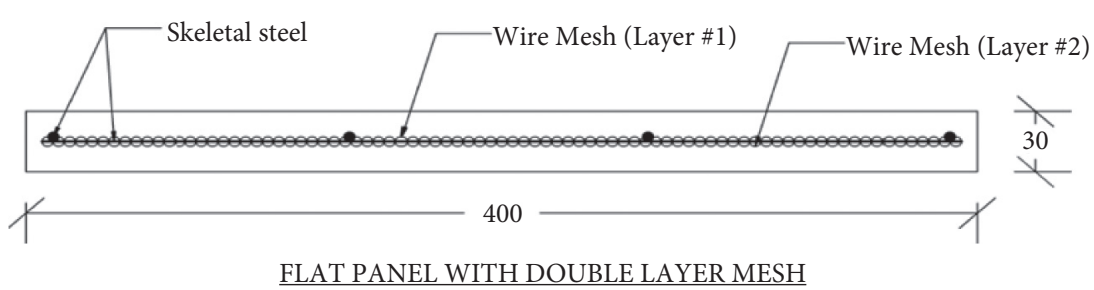

(a)

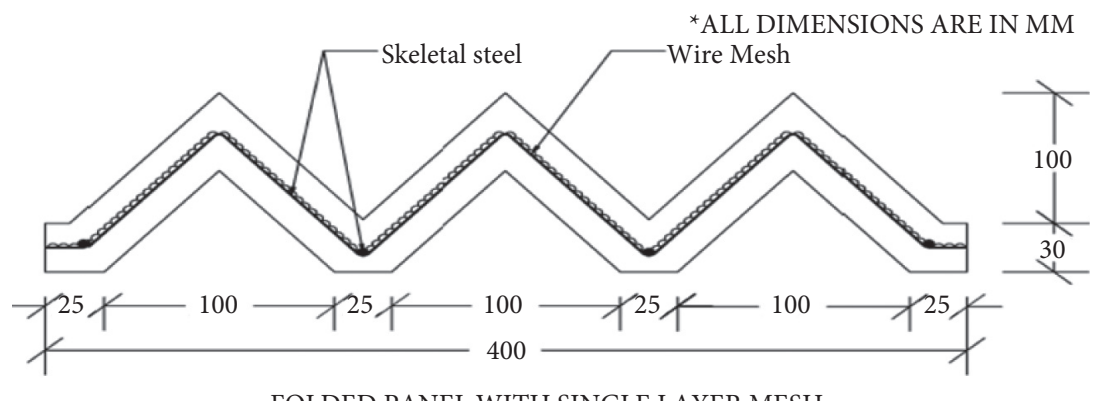

FOLDED PANEL WITH SINGLE LAYER MESH

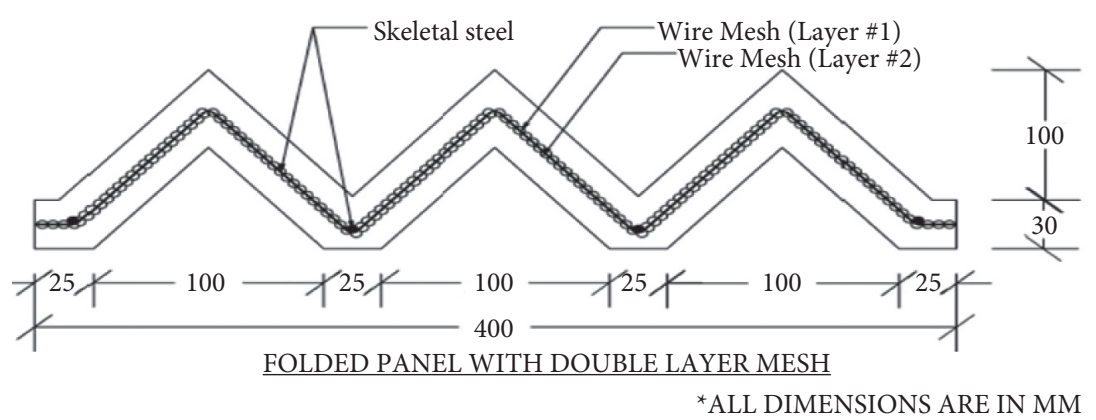

(b)

FIGURE 3: Geopolymer ferrocement panels with single and double layer wire mesh. (a) Flat panels. (b) Folded panels.

Flexure testing carried out on the folded panel is shown in Figure 9.

2.4.4. Drop-Weight Impact Test. The ability to absorb energy referred to as 'toughness' is of importance in the case of mesh-reinforced composites subjected to static, dynamic, and fatigue loads. The drop-weight impact test is a test meant for evaluating the impact characteristics of concrete/cement composites. The impact test was conducted using a $4.5 \mathrm{~kg}$ hammer, which was allowed to fall freely from a constant height of $460 \mathrm{~mm}$ through a guide at the center of the panel as per ASTM D2794-93 [22]. Specimens were placed in their position on a rigid platform. The mass was then dropped repeatedly, and the number of blows required to cause the first crack was recorded for each panel. The process was continued until the crack propagated further and appeared at the top surface of the specimen. At this point, the corresponding numbers of blows were noted. The impact test setup is shown in Figure 10.

\section{Experimental Results and Analysis}

3.1. Compressive Strength of the Geopolymer Mortar. Figure 11 shows the compressive strength of fly ash-based geopolymer mortar specimens in contrast to the control specimens. The geopolymer mortar comprised mostly of fly ash has a maximum compressive strength of $46.98 \mathrm{~N} / \mathrm{mm}^{2}$, 


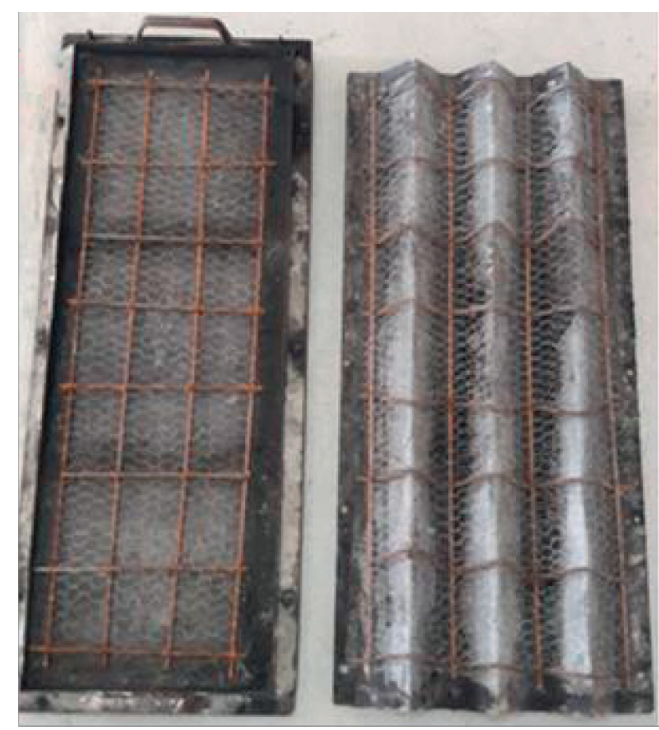

(a)

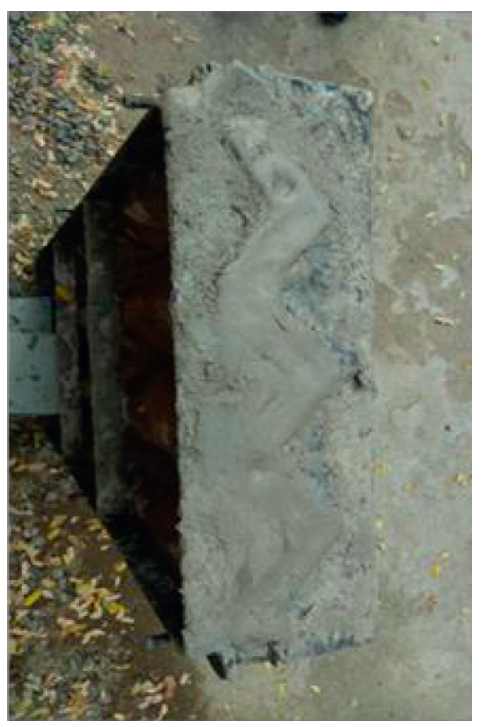

(b)

Figure 4: Fabrication and casting specimens. (a) Fabrication of reinforcement. (b) Casting specimens.

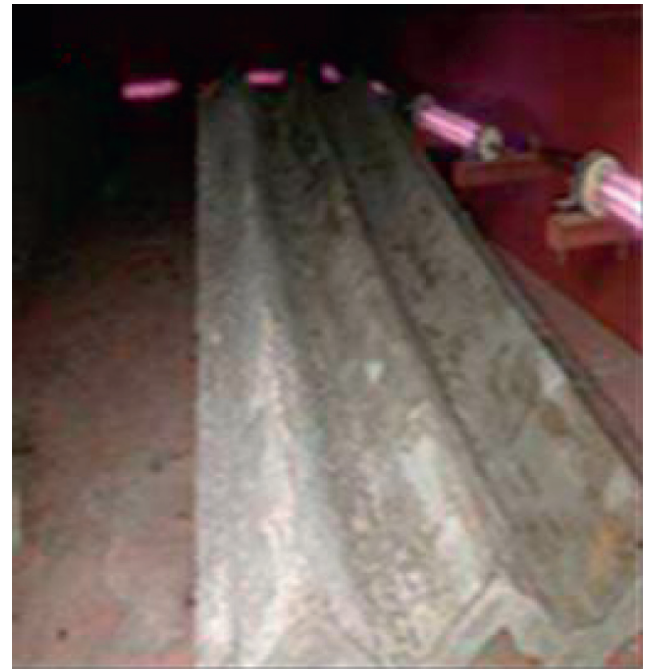

(a)

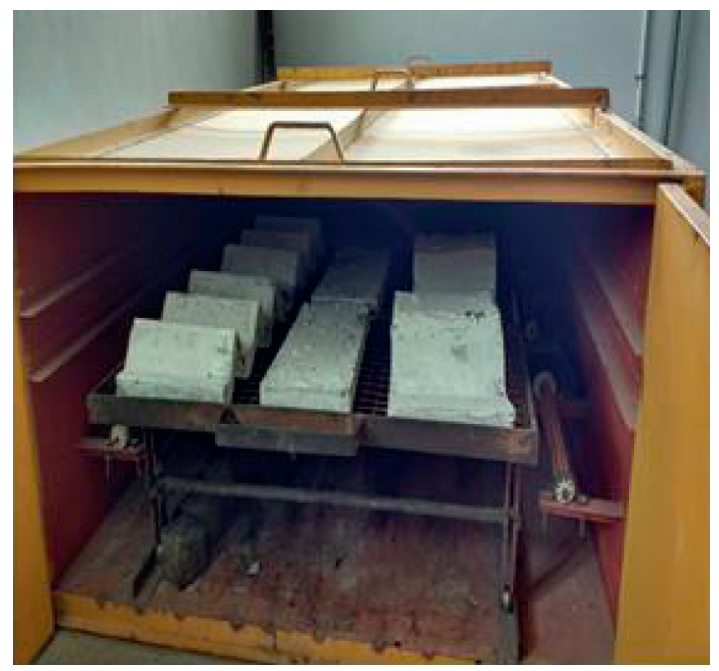

(b)

FIGURE 5: Curing specimens. (a) Specimens under curing. (b) Temperature-controlled heat curing chamber.

which is $19 \%$ higher than the compressive strength of control specimens. This increase may be attributed to the potential of the geopolymer in filling the pores, which eventually results in a closely packed microstructure. However, the specimens showed ductile behavior.

3.2. Flexural Strength of GF Panels. The load and corresponding deflection of GF panels are given in Table 4 . Moreover, the stiffness, ductility, and the amount of energy absorbed are included.

The obtained load-deflection variation for GF flat and folded panels is shown in Figure 12.

The volume, type, orientation, and inherent geometry of the strengthening mesh are the factors affecting the ultimate strength in relation to the position and the neutral axis. The strengthening properties consequently affect the ultimate strength. Table 4 shows the rise in ultimate strength as the number of wire mesh layers for flat and folded panels increases.

In flat geopolymer ferrocement panels, due to the increase in the number of wire mesh layers, the flexural strength has increased by $33 \%$. However; there is a $30 \%$ reduction in ductility. In the folded geopolymer ferrocement panel, there is no considerable effect on the flexural strength due to the increase in wire mesh layers. However, there is a $10 \%$ reduction in ductility.

Boosting the number of wire mesh layers has little impact on cracking, ultimate load, deflection, stiffness, ductility, and the level of energy absorption. This is because the wire mesh has been positioned in a zigzag plane to align the geometry of the folded panel as seen in Figure 3(b). Moreover, it does not complement the horizontal bending plane. However, the 


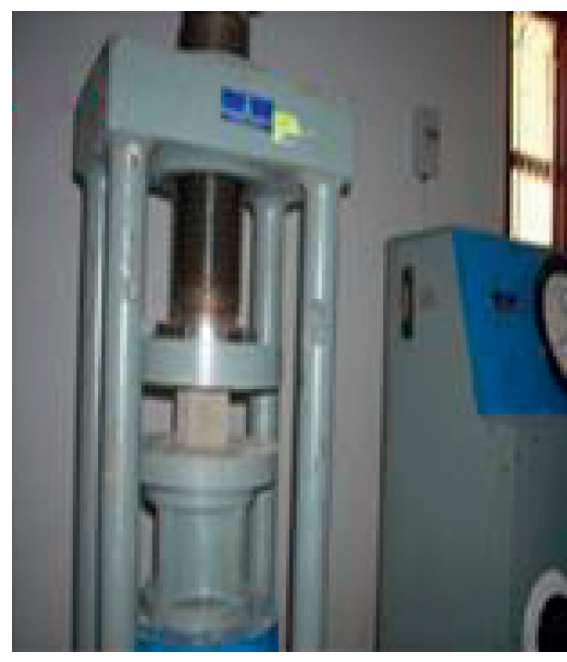

(a)

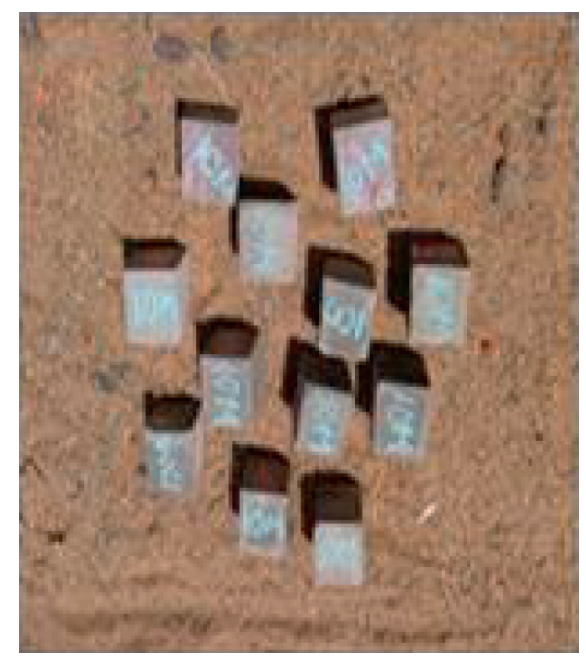

(b)

Figure 6: Compressive strength test. (a) Compression test on a mortar cube. (b) Geopolymer mortar cubes.

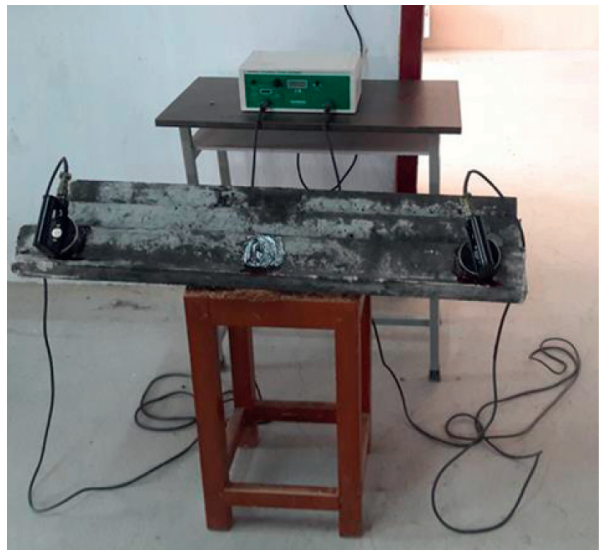

FIgURE 7: Ultrasonic pulse velocity test.

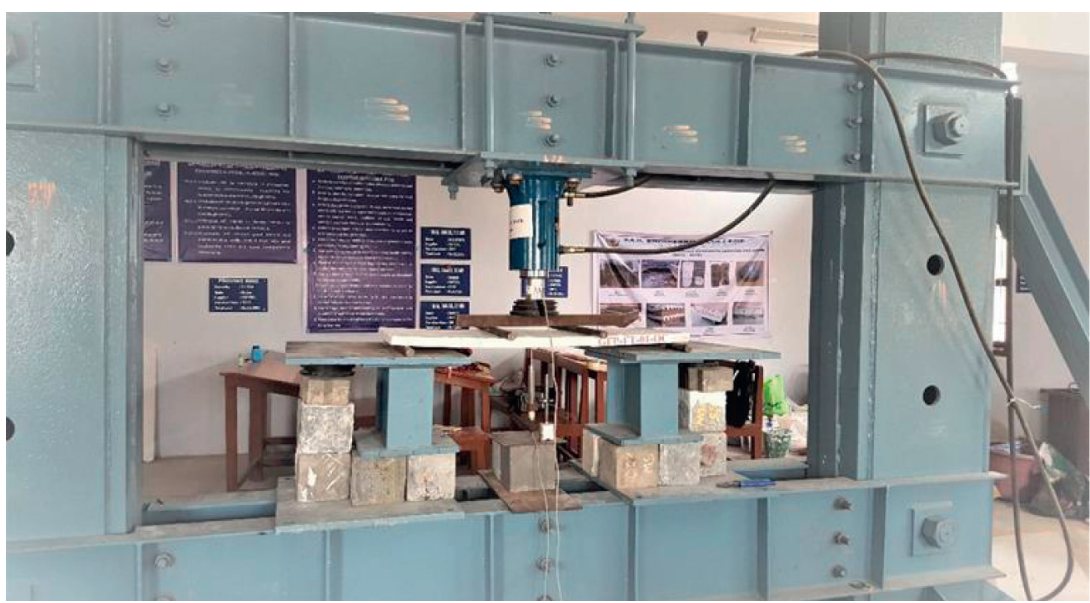

FIGURE 8: Flexural test on the GF flat panel.

cracking sequence has been altered by creating extra consistent cracks all along its span. As in the case of the portion, under compression, the load-deflection and stress-strain correlation for loading segments are defined by three phases (Kadhim
Sallal) [23], such as the elastic, elastic to plastic and plastic stages. The ending of the steeper linear part of the load-deflection curve correlates to the panel's first crack. Until this stage, no fracturing was noticed visually, although cracking was 


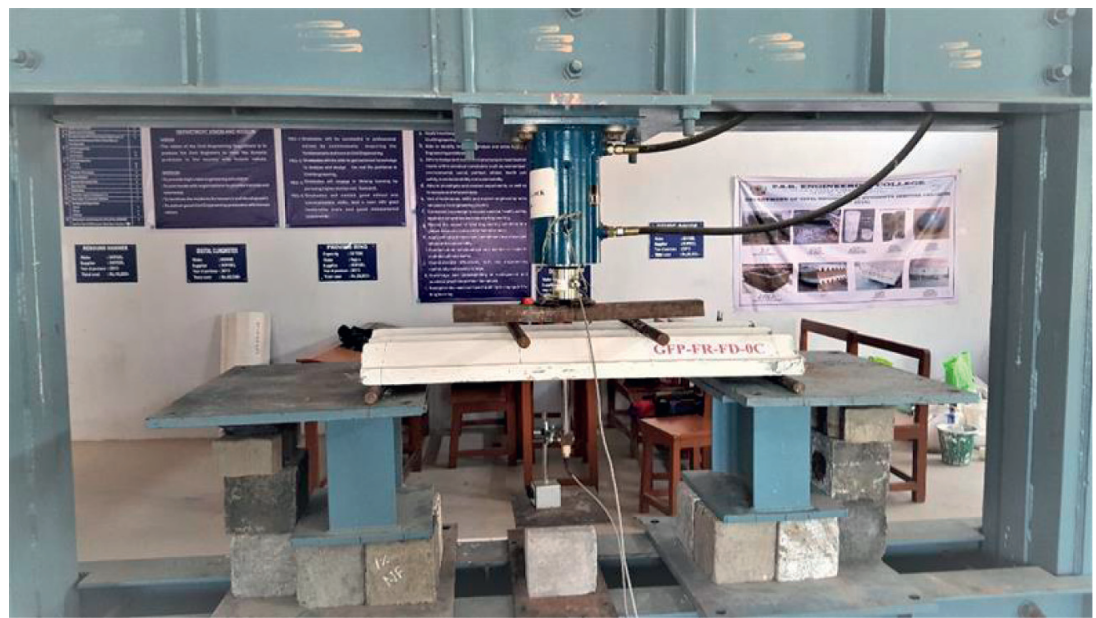

Figure 9: Flexural test on the GF folded panel.

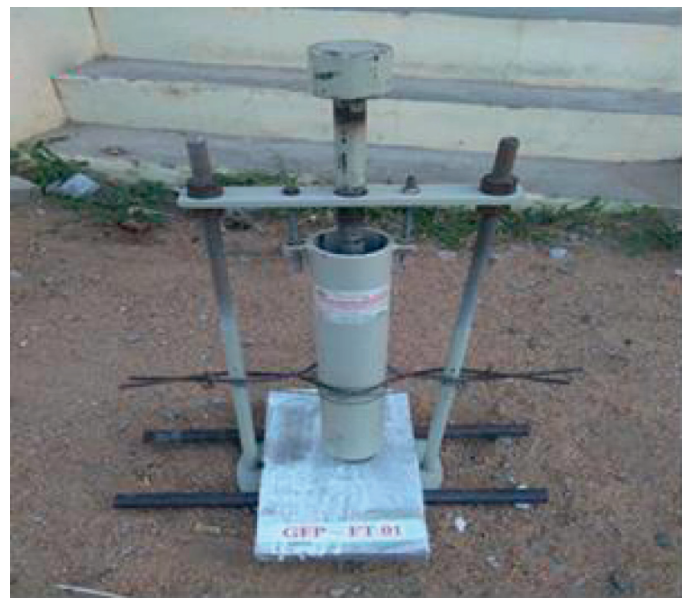

(a)

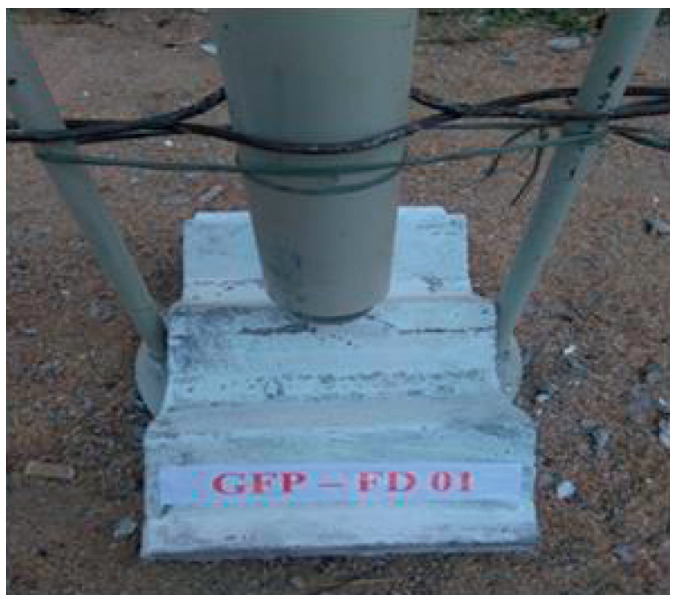

(b)

FIGURE 10: Drop-weight impact test on GF panels. (a) Test on flat panel. (b) Test on folded panel.

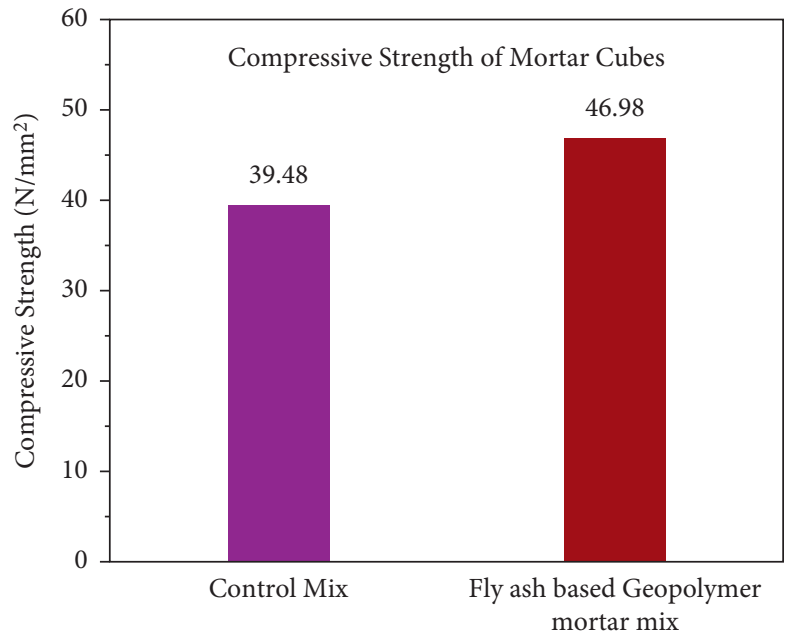

Cube Specimen

Figure 11: Compressive strength of the geopolymer mortar. 
TABLe 4: Load, deflection, and flexural strength of GF panels.

\begin{tabular}{|c|c|c|c|c|c|c|c|}
\hline \multirow{2}{*}{ Panel ID } & \multicolumn{2}{|c|}{ Cracking } & \multicolumn{2}{|c|}{ Ultimate } & \multirow{2}{*}{ Stiffness $(\mathrm{N} / \mathrm{mm})$} & \multirow{2}{*}{ Ductility } & \multirow{2}{*}{ Energy absorption (joule) } \\
\hline & Load $(\mathrm{kN})$ & Deflection (mm) & Load $(\mathrm{kN})$ & Deflection (mm) & & & \\
\hline GFP-FT-01-OC & 1.70 & 3.20 & 2.70 & 7.70 & 350.65 & 2.41 & 13.20 \\
\hline GFP-FT-02-OC & 2.10 & 3.50 & 3.10 & 5.90 & 525.42 & 1.69 & 10.60 \\
\hline GFP-FR-FT-OC & 2.30 & 3.70 & 2.90 & 6.30 & 460.32 & 1.70 & 11.40 \\
\hline GFP-FD-01-OC & 5.30 & 4.70 & 12.60 & 15.00 & 840.00 & 3.19 & 105.50 \\
\hline GFP-FD-02-OC & 4.60 & 5.10 & 13.00 & 14.90 & 872.48 & 2.92 & 104.00 \\
\hline GFP-FR-FD-OC & 7.20 & 4.90 & 13.90 & 11.00 & 1263.64 & 2.25 & 88.00 \\
\hline
\end{tabular}

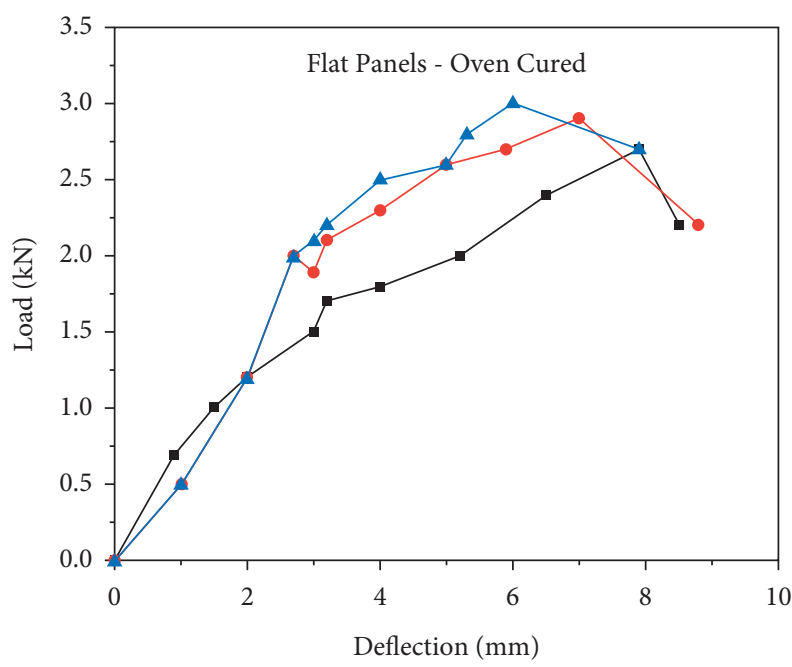

$$
\begin{aligned}
& - \text { GFP-FT-01-OC } \\
& \multimap \text { GFP-FT-02-OC } \\
& \simeq \text { GFP-FR-FT-OC }
\end{aligned}
$$

(a)

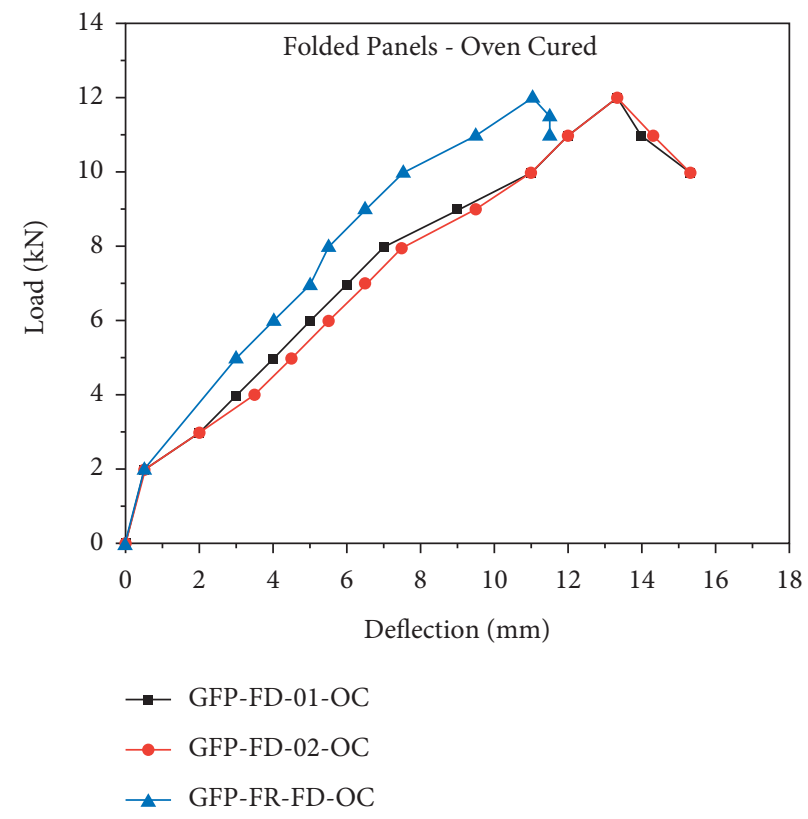

(b)

FIgUre 12: Load-deflection of GF panels. (a) Flat panels. (b) Folded panels.

always observed shortly after the load. In the second section of the curve (elastic to plastic level), multiple cracks are noticed and the steel stress is lower than the yield strain. At this point, as the steel quality increases, the distance and slope also increase. Steel yielding marks the conclusion of this stage and the beginning of the plastic stage.

With regard to fiber-reinforced GF panels, folded panels prove to be 3 times stiffer than the flat panels of wire mesh. In fiber-reinforced folded panels of single layer mesh, the crackings as well as ultimate load have increased by $35 \%$ and $10 \%$. The ultimate deflection and ductility, on the other hand, have decreased by $26 \%$ and $30 \%$, respectively, compared to the folded panels of a single and double layer mesh. In addition to this, the crack propagation and ultimate loads of fiber-reinforced folded panels were found to be 3.13 and 4.8 times greater than those of flat panels.

The cracking behavior of the ferrocement is explored by the observation of the number of cracks at the very first cracking and the aspects that induced their failure. Consequently, no observational results are available to trigger or validate the calculations for crack width estimation. Recently, there have been tests in relation to the variables known to calculate the crack width.
The cracking characteristics of flat as well as folded panels' geopolymer ferrocement could be seen in Figure 13.

Due to the weak compression field, preterm compression degradation was observed in flat panels having a single layer mesh at the upper end of the panel. However, the sequence of cracks was altered by increasing the number of wire mesh layers twice and by arranging the mesh far from the neutral axis. As a result, few other cracks occurred in the panel until it failed. Furthermore, as the fiber was inserted, consistent cracks were noticed across the length of the structure, and a desirable compression failure occurred at the final phase. Doubling the number of wire meshes resulted in a desirable compression failure in folded panels at the ultimate phase. This, however, did not influence the strength of the panel. Nevertheless, when the fiber is incorporated, the ultimate load improves significantly and the deflection at the ultimate phase reduces.

3.3. Impact Strength of GF Panels. The total energy absorbed by the GF panels when struck by a hard impactor depends on the local energy absorbed in the contact zone as well as by the impactor. The impact energy absorption can be obtained by using the following formula $[11,12]$ : 
TABLE 5: Impact resistance, impact energy absorption, and residual impact strength of GF panels.

\begin{tabular}{lcccccc}
\hline \multirow{2}{*}{ Panel ID } & \multicolumn{2}{c}{ Impact resistance (no. of blows) } & \multicolumn{2}{c}{$\begin{array}{c}\text { Impact energy } \\
\text { absorption (joules) }\end{array}$} & Residual impact strength ratio $\left(I_{\mathrm{rs}}\right)$ \\
& Cracking & Ultimate & \% increase & Cracking & Ultimate & 3.00 \\
\hline GFP-FT-01-OC & 4 & 12 & 2 & 77.69 & 233.08 & 2.66 \\
GFP-FT-02-OC & 6 & 16 & 1.6 & 116.54 & 310.78 & 5.17 \\
GFP-FD-01-OC & 20 & 132 & 5.6 & 388.47 & 2563.94 & 6.60 \\
GFP-FD-02-OC & 28 & 145 & 4.2 & 543.86 & 2816.45 & \\
\hline
\end{tabular}

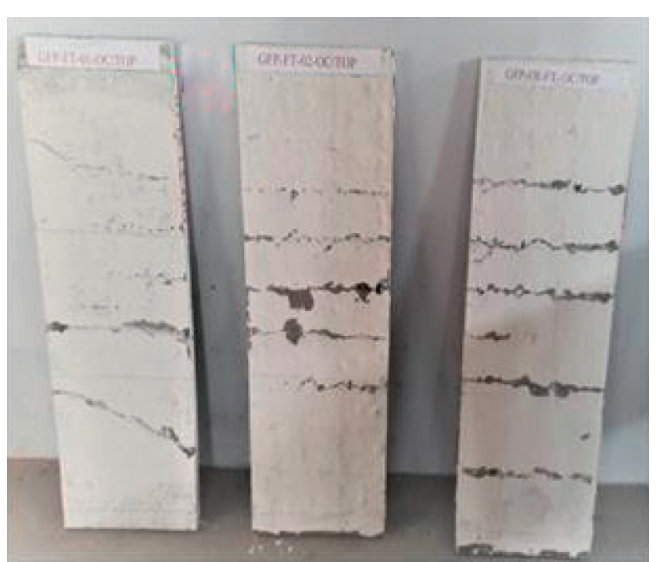

(a)

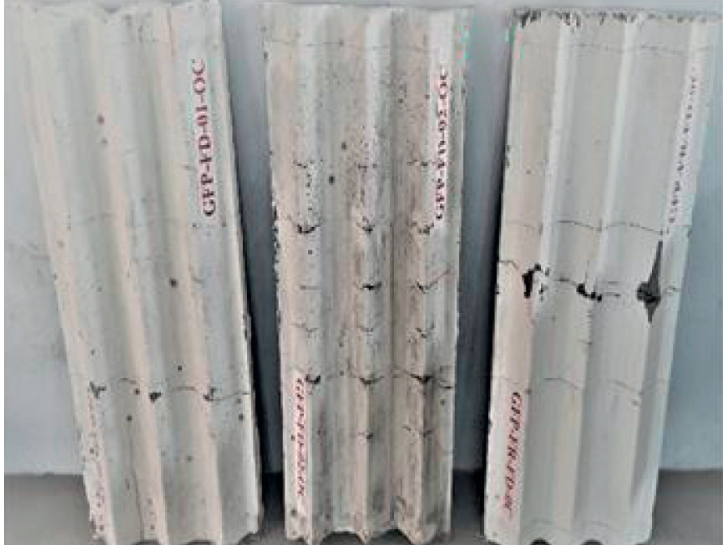

(b)

FIGURE 13: Cracking behavior of GF panels under flexure. (a) Flat panels. (b) Folded panels.

Impact energy absorption, $E=\left(\mathrm{N} \cdot \mathrm{m} \cdot \mathrm{v}^{2}\right) / 2$, where, the mass of the hammer, $m=w / g$; $w=$ weight of the hammer; $g=$ acceleration due to gravity; and impact velocity, $v=g . t$.

Height of fall, $h=(g . t)^{2} / 2$.

Time required for the hammer to fall from a height of $h$,

$$
\begin{aligned}
t^{2} & =\frac{2 h}{g} . \\
\text { Therefore, } E & =\frac{\left[N \cdot w / g \cdot(g \cdot t)^{2}\right]}{2} \\
& =\frac{\left(N \cdot w \cdot g \cdot t^{2}\right)}{2}=\frac{N \cdot w \cdot g \cdot(2 h / g)}{2} \\
& =N(w \cdot h),
\end{aligned}
$$

where $E=$ energy in joules; $w=$ weight in Newton; $h=$ drop height in meter; and $N=$ blows in numbers.

The ratio of energy absorbed at the failure of specimens to the energy absorbed at the initiation of the first crack is defined as the 'residual impact strength ratio' (Irs). The impact resistance, energy absorption, and residual impact strength ratio of GF panels at first crack and at ultimate are presented in Table 5, and the variation is shown in Figures 14 and 15.
3.3.1. Cracking Behavior of GF Panels due to Impact. From the impact test, the number of blows required to initiate the first crack was determined by visual observation, and the ultimate failure was determined based on the number of blows required for the crack to propagate to the sides of the panels. The impact energy absorbed by the GF panels was computed based on the number of blows required to cause the ultimate failure. The impact energy per blow as seen in Figure 14 shows the cracking behavior of GF flat and folded panels due to the impact load.

Moreover, the ultimate crack resistance generally increases with an increase in the volume fraction of reinforcement of the panels. This may be due to its higher ductility and lesser susceptibility to embrittlement of reinforcement. It is also observed that the failure pattern of the specimens exhibited localized failure at the point of contact of the drop weight. It is also noticed that no fragments detached from the specimens because various layers of the mesh reinforcement helped to hold different fragments together.

It can thus be inferred that the meshes used as reinforcement play a major role in not only improving the impact energy absorption, but also retaining/holding various fragments together. All panels failed due to spalling at the top face and scabbing at the bottom face. It is also observed that the crack patterns of all panels were similar. The failure pattern of GF panels is shown in Figure 16. 


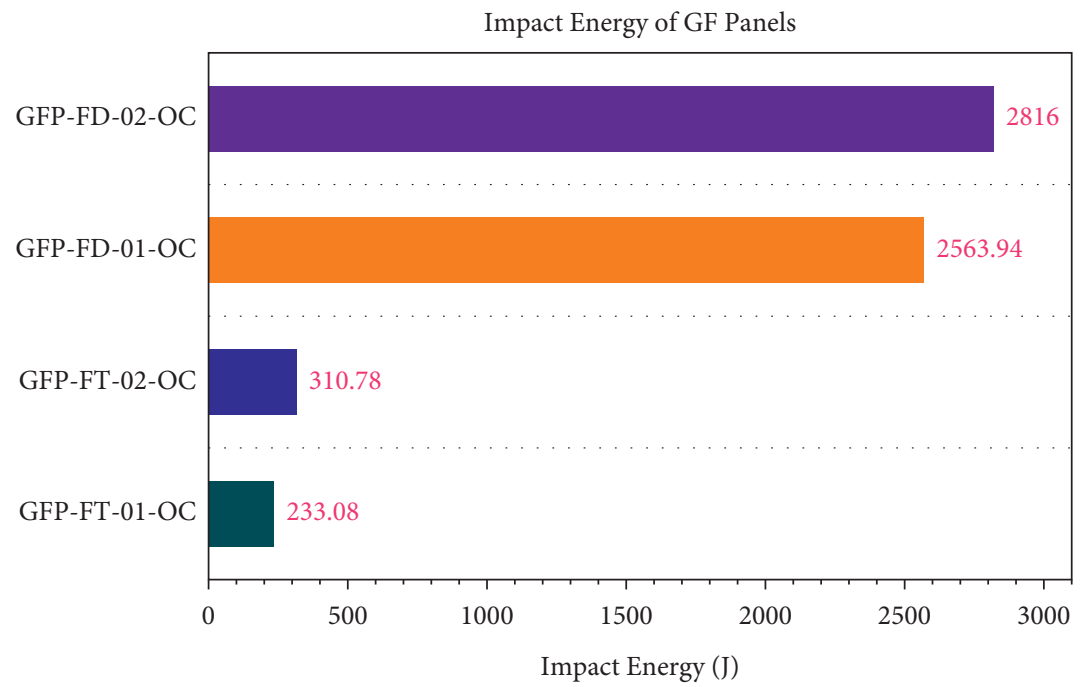

FIGURE 14: Energy absorption of GF panels under impact load.

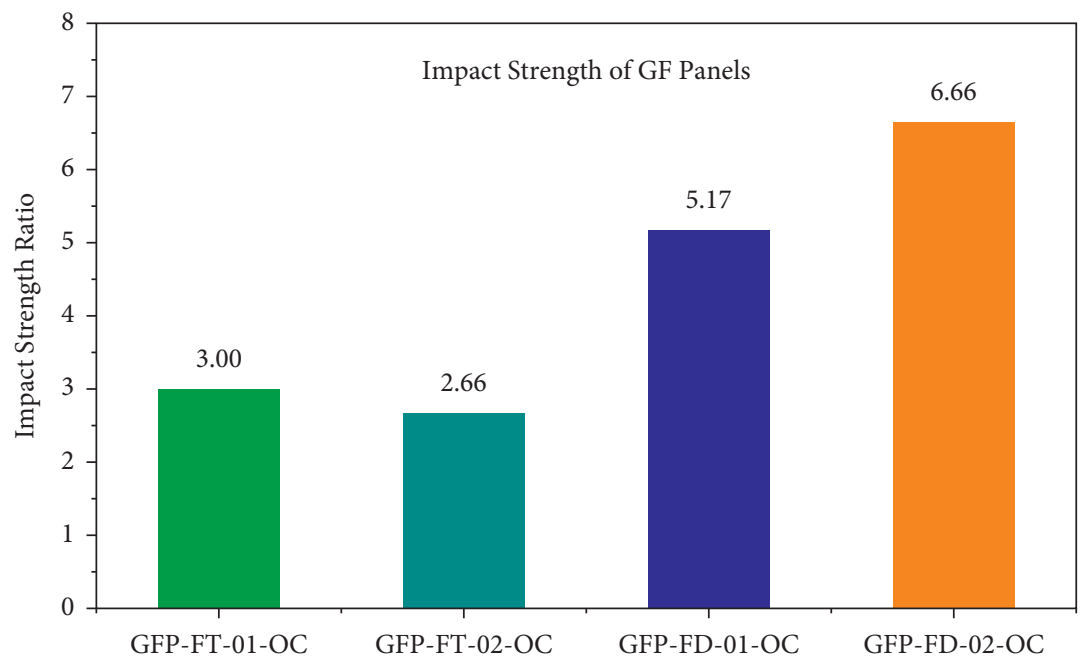

FIGURE 15: Residual impact strength of flat and folded GF panels.

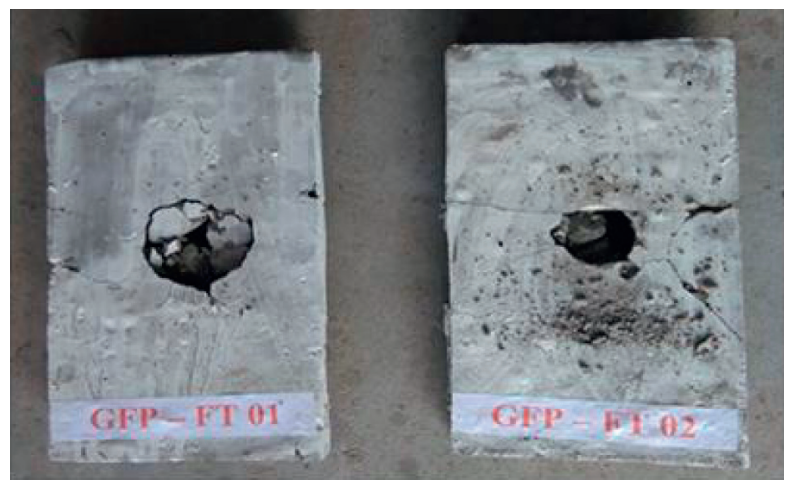

(a)

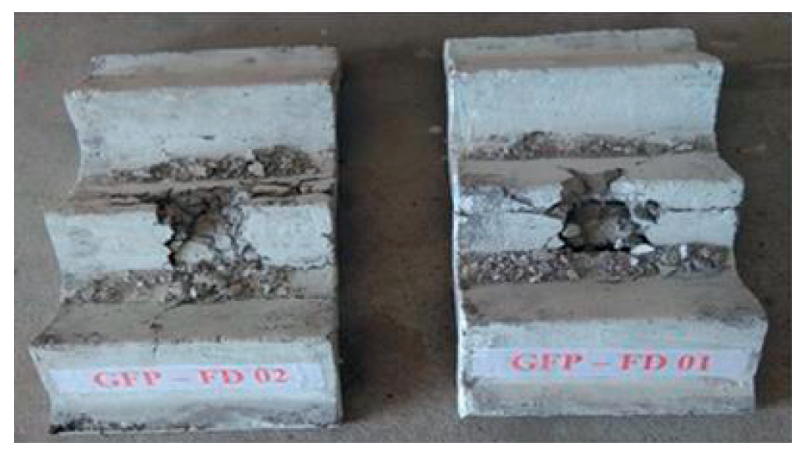

(b)

FIGURE 16: Cracking behavior of GF panels under impact. (a) GF flat panels. (b) GF folded panels. 


\section{Conclusions}

Based on the experimental test results of the geopolymer flat and folded ferrocement panels, the following conclusions are drawn:

(1) In flat geopolymer ferrocement panels, by increasing the number of wire mesh layers, the flexural strength increases by $33 \%$ and the ductility reduces by $30 \%$. In the folded geopolymer ferrocement panel, increasing the wire mesh layer has no considerable effect on the flexural strength. However, the ductility reduces by $10 \%$.

(2) The flexural strength of the folded geopolymer ferrocement panel is three times more than that of the flat panels. Moreover, the ductility of folded panels with single layer mesh and the fiber-reinforced panel increases by $32 \%$. It is also observed that the ductility of the panel with double layer mesh is $73 \%$ more than that of flat panels.

(3) In terms of cracking and ultimate load, flat and folded geopolymer ferrocement panels with double layer wire mesh and fiber-reinforced panels with single layer mesh behave similarly.

(4) When compared to the flat geopolymer ferrocement panels, the impact strength of the folded panels increased by $90 \%$, and the energy absorbed at failure due to the impact is directly proportional to the volume of the reinforcement provided in the panels.

(5) Due to the higher volume fraction of reinforcement, the failure pattern in the tested panels due to impact is found to be punching shear.

\section{Data Availability}

The data used to support the findings of this study are included within the article.

\section{Conflicts of Interest}

The authors declare that they have no conflicts of interest.

\section{Acknowledgments}

The authors express their gratitude and thanks to the Management of Thiagarajar College of Engineering, Madurai, and P.S.R. Engineering College, Sivakasi, for facilitating this study. The authors are also thankful to the Management of Ramco Institute of Technology, Rajapalayam, for their constant support towards research activities.

\section{References}

[1] J. Davidovits, "Global warming impact on the cement and aggregates industries," World Resource Review, vol. 6, no. 2, pp. 263-278, 1994.

[2] M. M. A. Abdullah, K. Hussin, M. Bnhussain, K. N. Ismail, and W. M. W. Ibrahim, "Mechanism and chemical reaction of fly ash geopolymer cement-a review," International Journal of
Pure and Applied Sciences and Technology, vol. 6, no. 1, pp. 35-44, 2011.

[3] ACI Committee 549, State-of-the-Art Report on Ferrocement, Report ACI 549-R97, American Concrete Institute, Michigan, USA, 1997.

[4] J. Temuujin, A. V. Riessen, and K. J. D. Mackenzie, "Preparation and characterisation of fly ash based geopolymer mortars," Construction and Building Materials, vol. 24, no. 10, pp. 1906-1910, 2010.

[5] D. Hardjito, C. C. Cheak, and C. H. Lee Ing, "Strength and setting times of low calcium fly ash-based geopolymer mortar," Modern Applied Science, vol. 2, no. 4, pp. 3-11, 2008.

[6] N. M. Mahmood and S. A. Majeed, "Flexural behavior of flat and folded ferrocement panels," Al-Rafidain Engineering, vol. 17, no. 4, pp. 1-11, 2009.

[7] M. Rajendran and N. Soundarapandian, "An experimental investigation on the flexural behavior of geopolymer ferrocement slabs," Journal of Engineering and Technology, vol. 3, no. 2, pp. 97-104, 2013.

[8] M. M. Rahman, S. Sameen, R. Hafiza, and M. A. Sadeque, "Behavior of polymeric fiber as an alternative reinforcement to iron wire mesh in ferrocement elements under flexural load," International Journal of Chemical, Environmental \& Biological Sciences, vol. 1, no. 5, 2013.

[9] D. H. Tran, D. Kroisova, P. Louda, O. Bortnovsky, and P. Bezucha, "Effect of curing temperature on flexural properties of silica-based geopolymer-carbon reinforced composite," Journal of Achievements in Materials and Manufacturig Engineering, vol. 37, no. 2, pp. 492-497, 2009.

[10] A. W. Hago, K. S. Al-Jabri, A. S. Alnuaimi, H. Al-Moqbali, and M. A. Al-Kubaisy, "Ultimate and service behavior of ferrocement roof slab panels," Construction and Building Materials, vol. 19, no. 1, pp. 31-37, 2005.

[11] S. Nagan and R. Mohana, "Behavior of geopolymer Ferrocement slabs subjected to impact," IJST, Transactions of Civil Engineering, vol. 38, pp. 223-233, 2015.

[12] G. Murali, A. S. Santhi, and G. M. Ganesh, "Impact resistance and strength reliability of fiber-reinforced concrete in bending under drop weight impact load," International Journal of Technology, vol. 5, no. 2, pp. 111-120, 2014.

[13] S. Kaliraj, P. Madasamy, and S. Dharmar, "Impact behaviour of geopolymer ferrocement trough panel," SSRG International Journal of Civil Engineering, pp. 496-500, 2017.

[14] J. Xie and O. Kayali, "Effect of superplasticiser on workability enhancement of Class F and Class C fly ash-based geopolymers," Construction and Building Materials, vol. 122, pp. 36-42, 2016.

[15] IS 3812 (Part 1), Pulverized Fuel Ash - Specification for Use as Pozzolana in Cement, Cement Mortar and Concrete, Bureau of Indian Standards, New Delhi, India, 2003.

[16] ASTM C618-5, Standard Specification for Coal Fly Ash and Raw or Calcined Natural Pozzolan for Use in Concrete, ASTM Standards, USA, 2005.

[17] R. H. Perry, Perry's Handbook for Chemical Engineers, McGraw-Hill, New York, USA, 1997.

[18] IS 383, Specification for Coarse and Fine Aggregates from Natural Sources for Concrete, Bureau of Indian Standards, New Delhi, India, 1997.

[19] R. J. Phalke and D. G. Gaidhankar, "Flexural behaviour of ferrocement Slab panels using welded square mesh by incorporating Steel Fibers," International Journal of Renewable Energy Technology, vol. 3, no. 5, 2014. 
[20] BS EN 1015-3, Methods of Test for Mortar for Masonry Determination of Consistence of Fresh Mortar (By Flow Table), European Standards, CEN, 1999.

[21] IS 4031 (Part 6), Methods of Physical Tests for Hydraulic Cement, Determination of Compressive Strength of Hydraulic Cement (Other than Masonry Cement), Bureau of Indian Standards, New Delhi, India, 1988.

[22] ASTM D2794-93, Standard Test Method for Resistance of Organic Coatings to the Effects of Rapid Deformation (Impact), ASTM Standards, West Conshohocken, PA, USA, 2010.

[23] A. Kadhim Sallal, "Different studies on ferrocement channel units under compression, flexure, fatigue and impact effect," International Journal of Research in Advanced Engineering and Technology, vol. 4, no. 2, pp. 41-48, 2018. 